\title{
Opportunities and Challenges for the Electronic Commerce Deployment in Saudi Arabia
}

\author{
Dr Asra Inkesar ${ }^{*} \quad$ Dr Shabana Maqsood ${ }^{2}$ \\ 1.Department Of Business Administration, Collage of Administration and Finance, \\ Saudi Electronic University, Riyadh, KSA \\ 2.Department Of Economics, Collage of Administration and Finance, \\ Saudi Electronic University, Riyadh, KSA
}

\begin{abstract}
.
To achieve success, it is important for businesses in Saudi Arabia to overcome challenges. The research reported in this paper shows that the most encountered challenges the development industry in Saudi Arabia is facing include: convincing decision makers, lack of EB strategies, organisational culture, ensuring customer satisfaction, international recognition, etc. This research also shows that, companies in the development industry have identified very similar challenges of EB as their counterparts in other industries in Saudi Arabia
\end{abstract}

Keywords: E-Business challenges, Development industry, Saudi Arabia.

DOI: $10.7176 / \mathrm{EJBM} / 11-35-07$

Publication date: December $31^{\text {st }} 2019$

\section{Introduction}

One of the most popular activities on the Web is shopping. It has much allure in it - you can shop at your leisure, anytime, and in your pajamas. Literally, anyone can have their pages built to display their specific goods and services. Electronic commerce (e- commerce) has been defined as the process of buying, selling, transferring or exchanging products, services, and/or information via computer networks, including the Internet (Turban, 2006). E-commerce includes consumers purchasing goods and services online; as well as businesses selling and communicating with other businesses through the Internet.

E-Commerce is not a new phenomenon. It has been around for at least three decades. Banks have used their own telecommunications lines since the early 1960s to transfer funds electronically from one branch to another and from one bank to another. This may be regarded as the earliest use of commerce executed by means of electronic data transferred through communications lines.

Ecommerce has a great deal of advantages over "brick and mortar" stores and mail order catalogs. Consumers can easily search through a large database of products and services. They can see actual prices, build an order over several days and email it as a "wish list" hoping that someone will pay for their selected goods. Customers can compare prices with a click of the mouse and buy the selected product at best prices. Online vendors, in their turn, also get distinct advantages. The Web and its search engines provide a way to be found by customers without expensive advertising campaign. Even small online shops can reach global markets. Web technology also allows to track customer preferences and to deliver individually- tailored marketing.

The basis for moving to an electronic commerce is a belief that electronic markets have the potential to be more efficient in developing new information-based goods and services, finding global customers and trading partners to conduct business. Electronic commerce via the Internet will change business institutions, operations and products/services as we know today, just as the telephone, TV, fax, and e-mail changed the way businesses and consumers communicate.

Therefore, e-commerce holds out enormous promises for producers in developing countries: easier access to the markets of developed countries especially B2C, and higher incomes resulting from these new trading opportunities.

\section{Background}

The World Wide Web is one of the most innovative technologies that changes the business environment and has a dramatic impact on the future of electronic commerce (EC). The future of EC will accelerate the shift of the power toward the consumer, which will lead to fundamental changes in the way companies relate to their customers and compete with one another (Slywotzky, 2000). E-commerce, defined as "the buying and selling of information, products, and services via computer networks" (Kalakota et al, 2004)) is radically changing the dynamics of the business environment and the way in which people and organizations are conducting business with one another. Lee (2001) suggests that e-commerce has altered the outlook of businesses from one focused on lean manufacturing (termed as economics of scarcity) to a focus on information, which he terms as economics of abundance. According to the definition of The Organization for Economic Cooperation and Development (OECD), Electronic Commerce or E-commerce as it is popularly called, refers to commercial trade in the open network integration, including that between the enterprise and enterprise (B2B), and that between the enterprise 
and consumer (B2C). Although transactions among businesses represent the bulk of electronic commerce, most attention has focused on business-to-consumer in Internet sales.

The Internet is reducing transaction costs, and reducing the benefits of optimal integration and optimal size. Small firms can buy services from outside more cheaply, thus barriers to entry are falling. By increasing price transparency and competition, the Internet is forcing companies to streamline their processes and eliminate inefficiency. They are doing so by closely working with customers and suppliers in order to offer a better service and a better price. More and more e-commerce is conducted over non-proprietary IT solutions, which reduces costs and offers better ways of communication between companies with different systems. By adopting ecommerce solutions, companies are gaining in efficiency and productivity and are offering better services that are available 24 hours a day, seven days a week (Pons et al., 2003).

The reason E-Commerce became so visible in the second half of the 1990s was the commercial aspect of the Internet. Once the Internet was opened to commercial activity, this worldwide network became the major carrier of business-to-business electronic data ex- change. The United Nations predicts $18 \%$ of purchases by firms and individuals will be conducted online by 2006 (UNCTAD, 2002). While the future of Web-based ecommerce in developed areas appears bright, consumers in developing countries, face a number of obstacles that may impact their view of e-commerce. Consumers and merchants in developing countries face a number of barriers to successful e-commerce, including less reliable telecommunications infrastructures and power supplies, less access to online payment mechanisms, and relatively high costs for personal computers and Internet access. These problems may cause consumers in developing countries to view e-commerce differently than consumers in developed countries.

Consequently, Electronic commerce has become very popular because of the benefits and the convenience it brings along. As shown in Table 1, the benefits include product promotion, cost saving, timely information, shortened remittance time, information consistency, better customer service, better customer relationship, customization of products, competitive advantages, and convenience of doing business (Wen et al., 2001). Electronic commerce is no longer an alternative, it is an imperative. The only choice open is whether to start quickly or slowly. Many companies are still struggling with the most basic problem: what is the best EC model? Unfortunately, there is no simple answer for this question. Even companies in the same industry, of the same size, or with similar cultures are finding that one EC model does not fit all. Companies are required to review their EC models and rethink strategy in order to capitalize on the changing dynamics of the marketplace.

\section{Global growth of e-commerce}

The Internet provides an open global network and access to this network is relatively cheap; that is simply the basic idea. This has led to claims that Internet-based e-commerce will grow rapidly and help producers in developing countries to overcome problems of exclusion from the world economy and improve the terms of their participation.

To understand E-Commerce one must understand both the technologies that serve as the infrastructure and the business models taking advantage of the technologies. Both technologies and business models currently used are innovative and fascinating. However, we must realize that within several years almost all commerce will be e-commerce to some extent. No one considers doing business via telephone or fax as t-commerce or f-commerce. It is only a matter of time before we realize that there is no reason to call business that is executed digitally via the Internet or other networks "e-commerce."

Table 1. The benefits of electronic commerce

\begin{tabular}{|c|c|}
\hline Benefit & Description \\
\hline Product promotion & $\begin{array}{l}\text { Through a direct, information-rich and interactive contact with customers, EC enhances } \\
\text { the promotion of products. Electronic medium also allows interactivity and customization } \\
\text { for advertising content, based on the customer profile or input. EC thus offers an } \\
\text { opportunity for new promotion strategies, enhancing the branding of products }\end{array}$ \\
\hline Cost saving & $\begin{array}{l}\text { By using a public shared infrastructure such as the Internet and digitally } \\
\text { transmitting and reusing information, EC systems lower the cost of delivering information } \\
\text { to customers, including personnel, phone, postage, and printing costs }\end{array}$ \\
\hline Timely information & $\begin{array}{l}\text { Due to their instantaneous nature, EC systems allow a reduction of the cycle time required } \\
\text { to produce and deliver information and services. }\end{array}$ \\
\hline $\begin{array}{l}\text { Shortened } \\
\text { remittance time }\end{array}$ & $\begin{array}{l}\text { With electronic funds transfer (EFT), customers send their remittances electronically to } \\
\text { the company's bank. This arrangement eliminates the time delay associated with the } \\
\text { remittance in the mail system }\end{array}$ \\
\hline $\begin{array}{l}\text { Information } \\
\text { consistency }\end{array}$ & $\begin{array}{l}\text { EC ensures the consistency and accuracy of information through sharing of information } \\
\text { and use of electronic forms for doing business }\end{array}$ \\
\hline
\end{tabular}




\begin{tabular}{|c|c|}
\hline Benefit & escription \\
\hline custome & \\
\hline $\begin{array}{l}\text { Better custome } \\
\text { relationship }\end{array}$ & \\
\hline & \\
\hline & $\begin{array}{l}\text { reduced advertising/ promotion costs; } \\
\text { products and timely response to } \\
\text { relationships and better customer serv }\end{array}$ \\
\hline & \\
\hline \multicolumn{2}{|c|}{$\begin{array}{l}\text { If the promise of e-commerce is to be realized, poor countries must improve Internet access and get 'e- } \\
\text { ly'. This is one of the core ambitions of the Digital Opportunities Task Force that was established by the } \\
\text { ernments of the G8 countries in 2000. But maximizing the benefits from e-commerce opportunities requires } \\
\text { roader strategy of both 'e-readiness' and 'commerce-readiness'. It also requires a healthy degree of } \\
\text { oticism about promises of dramatically reduced transaction costs and trade without intermediaries }\end{array}$} \\
\hline \multicolumn{2}{|c|}{$\begin{array}{l}\text { The rapid growth rate of Business-to-Business (B2B) E-commerce is being driven in large part by the } \\
\text { onential expansion of B2B exchanges and the new environment they offer for relationship building, access to } \\
\text { ds, and opportunities to participate in ways both large and small that were inconceivable only a few years ago. } \\
\text { low-cost connectivity and universal standards provided by Internet technology are the driving force behind } \\
\text { explosion of e-commerce activities nowadays (Laudon \& Laudon, 2008). }\end{array}$} \\
\hline \multicolumn{2}{|c|}{$\begin{array}{l}\text { Online retail sales in the U.S. are expected to grow about } \$ 20 \text { billion to } \$ 30 \text { billion each year for the next } \\
\text { years, reaching somewhere between } \$ 215 \text { billion and } \$ 335 \text { billion by } 2012 \text {, according to two recently } \\
\text { ased reports on e-commerce. }\end{array}$} \\
\hline \multicolumn{2}{|c|}{$\begin{array}{l}\text { In } 2007 \text {, non-travel-related e-commerce sales reached } \$ 175 \text { billion, a } 21 \% \text { increase over the previous year, } \\
\text { ording to Forrester Research Inc. In its report, titled "U.S. E-Commerce Forecast: } 2008 \text { to } 2012, \text {, Forrester } \\
\text { licts that online retail sales will reach } \$ 204 \text { billion in } 2008, \$ 235.4 \text { billion in } 2009, \$ 267.8 \text { billion in } 2010 \text {, } \\
1 \text { billion in } 2011 \text {, and } \$ 334.7 \text { billion in } 2012 \text {. Since the late } 1990 \text { s, e-commerce has been the subject of a lot } \\
\text { ype and attention. And recently, more specifically it is business-to-consumer (B2C) e-commerce which has } \\
\text { a receiving the most public attention. }\end{array}$} \\
\hline \multicolumn{2}{|c|}{$\begin{array}{l}\text { eMarketer, the world's leading provider of Internet statistics, also recognized as the authority on business } \\
\text { ine, reveals in their report (eMarketer, 2009) that B2C online sales in the USA alone (excludes travel, digital } \\
\text { wnloads and event tickets) will comfortably pass the } \$ 200 \text { billion mark in } 2013 \text {, reaching a new record total, } \\
\text { ich eMarketer projects will be } \$ 203.5 \text { billion with an increasing ratio of } 10.3 \% \text { comparing with the year } 2009 \text {. } \\
\text { oking at the Middle East, a recent report showed that the value of ecommerce has exceeded } \$ 4.87 \text { billion in } \\
\text { wait, Lebanon, Saudi Arabia and the UAE in } 2007 \text {. The analysis, which was based on face-to-face surveys in } \\
\text { wait and Lebanon, and online surveys in Saudi Arabia and the UAE, found that more than } 5.1 \text { million people } \\
\text { the four countries engaged in some form of e-commerce in } 2007 \text { (Field, 2008). }\end{array}$} \\
\hline
\end{tabular}

\section{E-commerce in developing countries}

Developing countries are home to more than $80 \%$ of the world's population, and are the site for growing use of ecommerce. There are theoretical claims that e-commerce could bring significant benefits to firms in developing countries, but we know very little empirically about the actual outcomes of e-commerce implementation (Molla \& Heeks, 2007).

There is tremendous potential for e-commerce in developing countries. While the base of Internet use in these countries has been relatively low, the rate of growth has been high. Between 2000 and 2011 developing countries' Internet user population grew by more than $1500 \%$ to roughly 1500 million as shown in Figure 1 , increasing their global share of all Internet users from 25\% to 75\% (MiniWatts, 2013). Despite the apparent benefits derivable from e-commerce adoption and use, Small to Medium Enterprises (SMEs) are slower to adopt the technology compared to their large business counterparts.

This is particularly the case in developing economies such as Indonesia where factors such as the lack of telecommunication infrastructure (Sheth \& Sharma, 2005), low average income of the population, the lack of credit card penetration (Hawk, 2004), as well as cultural barriers (Hawk, 2004; Paul, 2002), further restrict the viability of using e-commerce technologies. Ironically, the rate of Internet users in the Middle Eat which 
includes mostly Arab countries is very low 21.3\% compared to the population, even less than the world average $21.9 \%$, which is not the case in USA, and Canada where the rate exceed $70 \%$ of the population (Figure 2). Therefore, as global competition increases, nations are forced to adopt new trading practices in order to gain market share and increase export revenues. Liberalizing and opening the economies has become an imperative to survival in the global community, but one that also often jeopardizes local culture and beliefs. The need to use more sophisticated methods, to improve the telecommunication environment, to adopt common and harmonized procedures and standards, make electronic commerce and other information technology solutions valuable options to pursue in improving regional trade. Furthermore, the focus on implementing technology to enhance trade at the regional level also presents an opportunity to increase total Arab trade without sacrificing culture and beliefs.

Figure 1. Internet users (in millions) in the world by geographic region

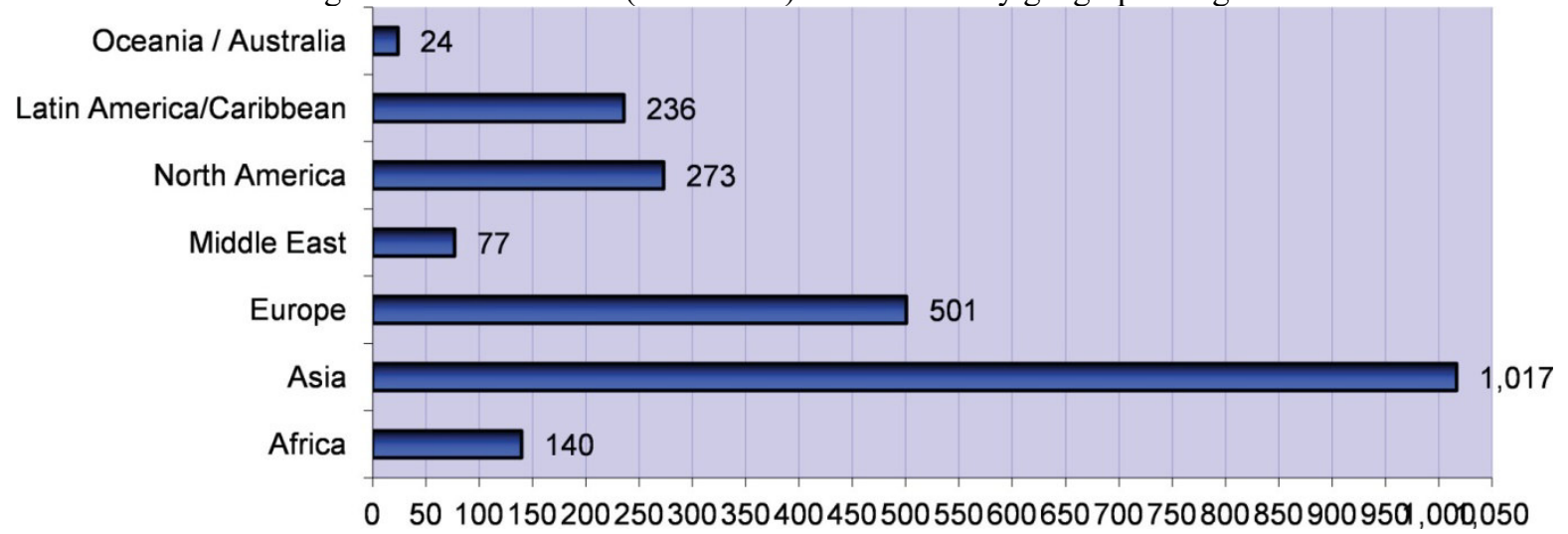

Figure 2. World Internet penetration rates by geographic region

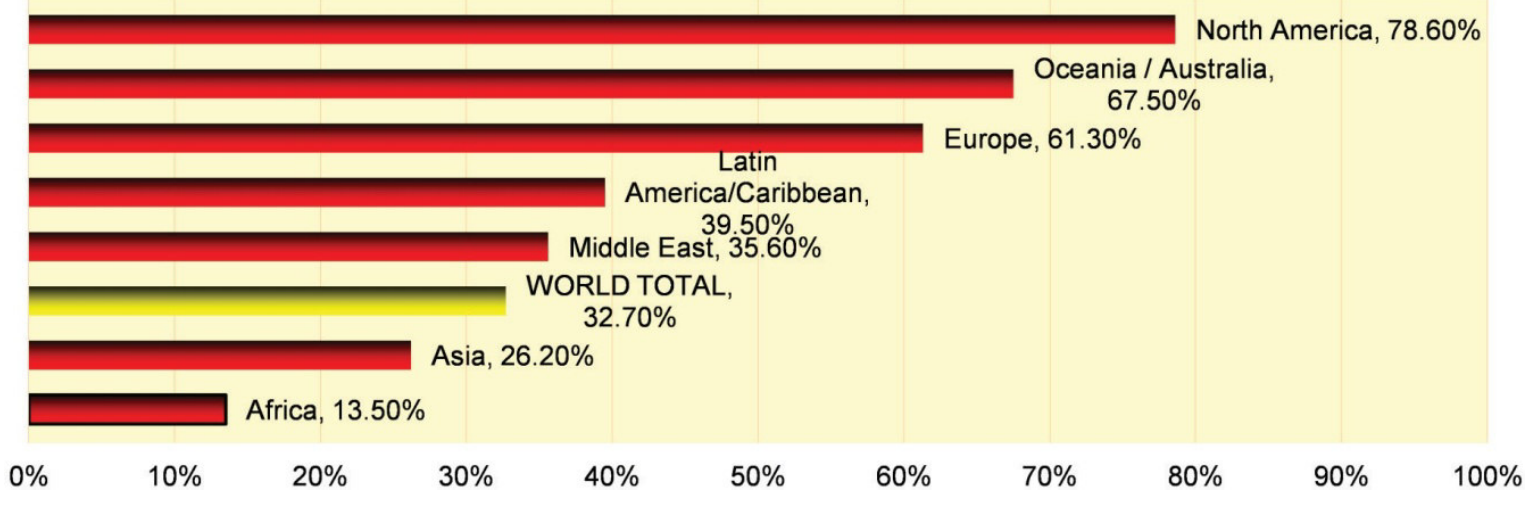

E-commerce situation in Saudi Arabia

According to Ansari \& Alhazemi (2016) the people of Saudi Arabia including Saudis and Non-Saudis were aware about the concept of online shopping, and its scope. However, they were not aware of the benefits mainly the competitive prices offered on online shops. It seems that due to the lack of awareness about the benefits of online shopping they were not buying much online. The enablers of online shopping such as use of smart phone, tablets, laptops and internet were very encouraging. Another study by Ansari (2016) found that the people were well aware of online shopping concept, they were interested in buying online. In comparison to non-Saudis, Saudis were more interested, the study found that females were more interested than males in online shopping, psychographic factors did not influence the online shopping behaviour however, store-variables played important role in online shopping decision. Another study of Ansari (2017) conducted in Saudi Arabia suggested that navigation aspects were more preferred than e-interactivity by the e-customers on the e-retail stores while shopping online. To convert the prospective visitors into customers the e-retailers should emphasize more on navigation factors such as clarity of the website, informativeness of the website, speed of the website, organization of the website, effectiveness of the website, overall structure of the website, easy navigation on website, and ease of use of the website. Ansari \& Qadri (2018), found that the image of the online retailers played important role in encouraging the online shopping. Ansari (2018) concluded that social class and cultural factors significantly influenced the online shopping behaviour of the e-consumers. Another study of Eid (2011) showed that B2C e-commerce customer loyalty in Saudi Arabia was strongly influenced by customer satisfaction but weakly influenced by customer trust. 
Saudi Arabia has the biggest IT market in the Gulf region, with spending of US\$ 3.4 billion in 2008 expected to rise to US\$ 5.6 billion by 2013 , a compound annual growth rate (CAGR) of $11 \%$. The IT market should continue to grow, driven by a robust economy and infrastructure investments in major verticals such as oil and gas, power, financial and telecoms (Business Monitor International, 2009).

BMI predicts that per-capita IT spends will rise $42 \%$ to US\$ 200 by 2013 , with PC penetration also rising, to nearly $30 \%$. Saudi Arabia accounts for around $40 \%$ of IT spending in the Middle East region. Youthful population demographics, a regional economic boom fuelled by high oil prices and a buoyant real estate sector, and specific factors such as the growing popularity of e-banking, will all drive retail growth. In 2008 substantial budgets were leveraged for e-government infrastructure development. Manufacturing and trading firms are seeking efficiencies, while demand for advanced IT services such as outsourcing, is expected to show a strong growth trend.

The most dramatic growth will be in broadband penetration, which is projected to rise from $6.4 \%$ last year to $31.2 \%$ by 2013 . By 2012 , there will be an estimated 8.9 million broadband users in the Kingdom. Investment in broadband and government initiatives has seen an improvement in e-services development and utilization, which was reflected in the UN's most recent e-government rankings, in which Saudi Arabia raised 10 places.

The Arab Advisors Group has released the results of a survey showing that e-commerce has achieved noteworthy popularity in the Kingdom of Saudi Arabia. The survey showed that $48.36 \%$ of Internet users in Saudi Arabia had purchased products online or using their mobile phones in the last twelve months. That represents more than 3.5 million e-commerce customers, or $14.26 \%$ of the Kingdom's total population. The results have estimated that these transactions totaled $\$ 3.28$ billion (Smith, 2008).

An earlier study published by the Communications and Information Technology Commission (2007), Saudi Arabia, reveals that Internet penetration in Saudi Arabia was $49 \%$ out of the total population and nearly one third of the Saudi population have used Internet at least in the last 2 weeks.

Recent statistics cited by MiniWatts Marketing Group from the Internet World Stats reveals that Saudi Arabia has 13,000,000 Internet users as of June 2012, in comparison to 1,500,000 in 2003 (see Table 2). This indicates that the Internet use in Saudi Arabia has nearly duplicated ten times in a space of nine years (MiniWatts, 2013).

Moreover, according to the Saudi Network Information Center (2009), more than 27290 new Internet domain names have been registered in Saudi Arabia under the top level domain of Saudi Arabia (.sa) as of February 2012 in comparison to 110 domain names were registered in 2002. (Figure 3)

Table 2. Internet growth and population statistics in Saudi Arabia

\begin{tabular}{|l|l|l|l|}
\hline YEAR & Internet Users & Population & \% Pop. \\
\hline 2000 & 200,000 & $21,624,422$ & $0.9 \%$ \\
\hline 2003 & $1,500,000$ & $21,771,609$ & $6.9 \%$ \\
\hline 2005 & $2,540,000$ & $23,595,634$ & $10.8 \%$ \\
\hline 2007 & $4,700,000$ & $24,069,943$ & $19.5 \%$ \\
\hline 2009 & $7,761,800$ & $28,686,633$ & $27.1 \%$ \\
\hline 2010 & $9,800,000$ & $25,731,776$ & $38.1 \%$ \\
\hline 2012 & $13,000,000$ & $26,534,504$ & $49.0 \%$ \\
\hline
\end{tabular}

On the other hand, the Saudi Government has given the e-commerce issue a noticeably consideration and established a standing committee on e-commerce in February 1999 under the chairmanship of the undersecretary of State for the Ministry of Commerce for Technical Affairs. It has also launched a portal in 2005 , providing some government services (www. yesser.gov.sa). However, the effects of this portal are still not evident due to its recent launch and have still not exhibited the effects of the local perception of e- commerce. The Ministry of Education in Saudi Arabia, under the auspices of the royal authorities, has taken up initiatives to introduce an Information Technology to students in its educational institutions through two project: "Watany," which is a project that envisages provision of a computer per ten students, connecting all schools with the national network, and providing LAN service in each school, while "Ta'heel" is a two year training course in five areas of informatics: desk top techniques, system development, Internet, computer networks, and computer maintenance for high school graduates. The main goal of those projects is to educate people on how to operate the system and use the Internet as well as leveraging their Information Technology (IT) skills.

It is quite obvious from the previously mentioned figures and statistics that the Internet is now being embraced by Saudi business. However, e-commerce is still in its infancy. Contacts will sometimes have e-mail addresses on their business cards but this is by no means a certainty. It is still quite common for business people (and some government officials) to use a Hotmail or yahoo style address rather than a corporate domain (NZTE, 2006).

Mobile e-commerce

In Saudi Arabia, the concept of mobile commerce ( $\mathrm{m}$ - commerce) has incited significant interest over recent 
years and benefitted from considerable development.

Figure 3. Number of registered domains in Saudi Arabia up to 2012

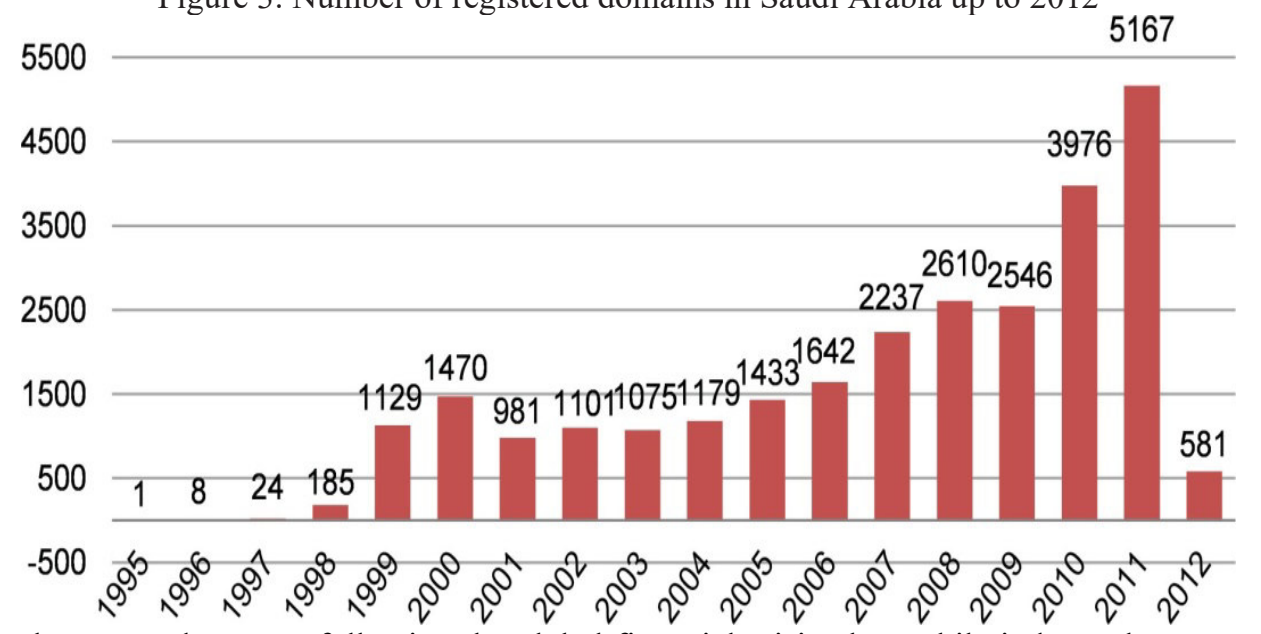

Despite the recent downturn following the global financial crisis, the mobile industry has stayed relatively unscathed. With the so-called smart phone revolution, where advanced mobile devices are starting to see massadoption, the demand for more sophisticated mobile services is on the rise. Moreover, the penetration of mobile phone handsets and the diffusion of mobile technologies have been dramatically increasing in recent years.

Mobile users are able to gain access to information in real-time, and can communicate and purchase anywhere, at any time. As can be seen through such advantages, m-commerce provides a key innovation, and induces a number of opportunities, particularly for organizations. Furthermore, it is considered that user satisfaction may be significantly enhanced through $\mathrm{m}$-commerce, thus providing the potential for user behaviors to be promoted and user satisfaction enhanced (Alkhunaizan \& Love, 2013).

According to a recent study by on global mobile data traffic forecast, Smartphones represent only 12 percent of total global handsets in use today, but they represent over 82 percent of total global handset traffic. Moreover, the number of mobile phone subscriptions reached almost 6,000 million at the end of the previous year, representing a penetration rate of 86.7 percent worldwide and 78.8 percent in developing countries (Alwahaishi \& Snasel, 2013).

\section{Immaturity of e-commerce}

The immaturity of e-commerce could be referred to three major factors; educational (illiteracy and lack of computer related skills), cultural/ethical (confidence in the products and the availability of redress), and technical (speedy transport and efficient payment systems) factors.

\section{Human development factor Illiteracy}

A major remark is it seems important from the data in Table 3 that the number of illiteracy is increasing over the world from 1970-2000 (847million to 862 million). If we try to analyze the details of the table is that: The number of illiteracy is decreasing over the period of 1970 till 2000, and it is estimated to be reduced to 35 million in 2015 Only in more developed countries that, which is not the case in the Arab countries, it started with 48 million and grew to 67 million in 2000, and it is estimated to be raised to 71 million. Even the statistics demonstrate that the situation is critical for Saudi Arabia, where the adult illiteracy rate (age 15 and above) is about $16 \%$ of the total, taking in consideration that $60 \%$ of the population are aged $15-64$, comparing to the illiteracy rate of most of the EU countries, Canada and the US countries which is $0 \%$ (UNESCO, 2008).

The increasing of the rates of illiteracy is an indicator of the low education and the same time it could be considered as an obstacle to the local and International firms to reach the Saudi consumers.

\section{Lack of Computer-Related Skills}

Another factor that may have a negative effect on the accessibility to the Saudi market is the low skills in computer, both the providers and users of Internet- based services require new skills. The lower the skills base, the higher the cost for implementing information technology and training in Saudi Arabia - and the lack of information about the consumer behavior are variables that can be the rationale way for introducing e-commerce by firms in developing countries.

Saudi Arabia has low penetration rates in 2007 for proportion of households with computers and Internet of $43 \%$ and $35 \%$ respectively, comparing to $79 \%$ and $74 \%$ and $83 \%$ and $79 \%$ for Singapore and Sweden respectively (ITU, 2009). 
Table 3. Adult illiteracy rate globally and in the Arab World

\begin{tabular}{|l|l|l|}
\hline Years & World & Arab \\
\hline 1970 & 847 & 48 \\
\hline 1980 & 871 & 55 \\
\hline 1990 & 879 & 62 \\
\hline 1995 & 872 & 65 \\
\hline 2000 & 862 & 67 \\
\hline 2005 & 847 & 69 \\
\hline 2010 & 824 & 71 \\
\hline 2015 & 799 & 71 \\
\hline
\end{tabular}

\section{Technical factors}

Countries are usually at very different starting positions in the task of building their digital infrastructure to facilitate the development and diffusion of e-commerce applications. A robust, well-functioned financial sector is vital for economic growth and successful electronic activities, especially for developing countries.

\section{Speedy Transport}

There is no point trying to sell products that cannot be delivered at reasonable cost to the buyer's desired location. For digital products this is not a problem, but most developing country exports are not digital, they are materials. Electronic transactions often raise expectations for faster delivery, making the transport infrastructure even more critical for the development of e-commerce. The policy lesson is that addressing the 'old' issues of providing efficient road and rail links, port facilities and fast customs clearance is essential for operating in the "new economy'.

\section{Efficient Payment Systems}

E-commerce requires low-cost and reliable payment systems. While various solutions to the problem of payments for e-commerce transactions are being developed, it is essential that banks in developing countries must participate to make these attributes of payment systems as a criterion of helping the firms to get access Saudi market.

Credit cards are important facilitators of e-commerce as they provide a credible payment channel for online transactions. However, because of the Islamic prohibition of interest, in Saudi Arabia, there has long been a debate about the acceptability of owning and using credit cards. Accordingly, Saudis were generally skeptical about credit cards during the early years of their introduction into the country. Saudi Arabia has a low CCPR (Credit Card Penetration Rate) of $15 \%$ comparing to $140 \%$ and $273 \%$ in Korea and Singapore for example (Karake \& Qasimi, 2006).

\section{Cyber Crime}

Moreover, today, the frequent instances of online crime such as hacking, cracking encryptions, information snooping, identity theft and so forth, are grim indicators of the blurred concept of Internet ethics for many users. Though these acts are comparable to real life criminal behavior such as theft, forgery, fraud, and so forth; many people fail to make this connection. Often this is attributed to the immediacy of the medium, the lack of face-toface interaction, and apparent anonymity. Also, the absence of social and penal deterrents is another significant factor. Often, instances of online vandalism and crime are perceived as achievements by both the perpetrator and society at large (Sait et al., 2007).

\section{Confidence in the Product}

Buyers must be confident that the product being purchased meets the desired specifications. Product specifications are becoming increasingly complex as industrialized economies impose norms relating to product safety and labeling, as well as for labor and environmental standards. This makes e- commerce purchasing more hazardous for the buyer.

\section{The Availability of Reimbursement}

As in all other forms of commerce, customers must be confident that they can obtain reparation if something goes wrong. The seller's assurance may not be sufficient. E-commerce may be enhanced by online ADR (alternative dispute resolution) mechanisms offering rapid, low-cost redress for disputed transactions. These mechanisms are not intended to replace (slow and expensive) court adjudication, but to supplement it.

To some extent, new e-commerce relationships are already providing some of the solutions to support transaction arrangements. E-commerce portals that bring together buyers and sellers are providing an increasing range 
of services - from secure payment systems to links with logistics providers, insurance providers and customs clearance services. There are also new private certification agencies developing online certification schemes addressing international quality standards and environmental and employment standards (ISO 9000, ISO 14000 and SA 8000, respectively). Certification schemes are being developed by intergovernmental organizations such as the European Union and the UN agencies as well as by producer associations in developing countries. Some service providers even offer to collect samples from potential suppliers and dispatch them to potential customers. Although such solutions are beginning to become available, their reach is likely to be confined to large producers in developing countries whose operations are based in large urban centers.

\section{Conclusion}

The e-commerce market is driven by a relatively conservative attitude and online culture, which has not yet opened up fully to online purchases and commerce in Saudi Arabia. Although large numbers of consumers are embracing e-commerce, there is still a struggle to full acceptance. Even though it being the electronic age with Internet usage growing at a tremendous rate, but when it comes to ordering online, organizations and individuals still face resistance. Thus, the e-commerce industry in Saudi Arabia has a daunting task of convincing customers of secure transactions and protection of personal data.

Much still needs to be done to encourage e-commerce in Saudi Arabia. Key steps include the rapid development of human resources, greater attention paid to e-literacy among citizens and activities to build capacity, particularly to provide a skills base among SMEs for ecommerce. Governments should encourage business start-ups and incubation projects that advance this activity, including through public- private partnerships.

In addition, policies need to address infrastructure development, which is key to the developing electronic commerce. Infrastructure that can play an important role for businesses includes cost-efficient communication technologies such as broadband, satellite connections and Voice over Internet Protocol (VOIP). It is important to raise awareness and to offer training programs that target the business community in particular and the public in general.

\section{Future Research Directions}

The Electronic Commerce services are still relatively new in Saudi Arabia, and probably immature, therefore, further research is needed to identify additional factors that facilitate adoption of E-commerce in this country. Searching for additional variables that will improve to understand the actual use and predict usage intention more accurately is necessary. It would be reasonable to add social influence and facilitating conditions, such as selfefficacy and technical support, to the research model. Moderating variables like age, education, and experience may also add more insight to the findings of future studies.

\section{References}

Alkhunaizan, A., \& Love, S. (2013). Effect of demography on mobile commerce frequency of actual use in Saudi Arabia. [). Springer Verlag]. Advances in Intelligent Systems and Computing, 206, $125-131$. doi:10.1007/978-3-642-36981-0_12

Al-Shohaib, K., Al-Kandari, A., \& Abdulrahim, M. (2009). Internet Adoption by Saudi Public Relations Professionals. Journal of Communication Management, 13(1), 21-36. doi:10.1108/13632540910931373

Al-Tawil, K. (2001). The Internet in Saudi Arabia. Tele- communications Policy, 25(8), 625-634. doi:10.1016/ S0308-5961(01)00036-2

Alwahaishi, S., \& Snášel, V. (2013). Consumers' Acceptance and Use of Information and Communications Technology: A UTAUT and Flow Based Theoretical Model. Journal of Technology Management \& Innovation, 8(2), 61-73. doi:10.4067/S0718-27242013000200005

Anderson, J. (2000). Producers and Middle East Internet technology: getting beyond impacts. The Middle East Journal, 54, 419-431.

Ansari Z.A. and Qadri, F.A. (2018), "Role of E-Retailers Image in Online Consumer Behaviour - Empirical findings from e-customers' perspective in Saudi Arabia”, International Business Research, Vol. 11(4), pp. $57-64$.

Ansari, Z.A. (2016), "Online Shopping Behaviour in Saudi Arabia - An Empirical Study”, International Journal of Advanced Research, Vol. 4 (5), pp. 689 - 697. DOI:10.21474/IJAR01

Ansari, Z.A. (2017), "Navigation versus E-Interactivity in Online Store: An Empirical study in Saudi Arabia", International Journal of Scientific Research and Education, Vol. 5 (10), pp. 6867 - 6877.

Ansari, Z.A. (2018), "Socio Cultural Influences on Online Shopping Behaviour", Journal of Business and Retail Management Research, Vol. 13 (2), pp. 255 - 263.

Ansari, Z.A. and Alhazemi, A.R. (2016), "An empirical study of the consumer awareness and acceptance of online shopping in Saudi Arabia”, International Journal of Development Research, Vol. 6 (2), pp. 6918 - 
6925.

Business Monitor International. (2009). Saudi Arabia Information Technology Report Q1. Retrieved July 13, 2013 from http://www.mindbranch.com/Saudi-Arabia- Information-R302-5249.

Communications and Information Technology Commission. (2007). Internet Usage in the Kingdome of Saudi Arabia. Retrieved May 29, 2013 from http:// www.citc.gov.sa/NR/rdonlyres/2DB93B05-EAFA- 4D8FA680-3AC5CAD2F45A/0/Internet_Usage_Study_in_KSAAll_sectorsEN.pdf.

eMarketer. (2009). eMarketer Revises E-Commerce Forecast for 2009. Retrieved January 10, 2013 from http://www.emarketer.com/Article.aspx?id=1006948.

Field, R. (2008). UAE leads in e-commerce poll. ITP Digital, 18(5). Retrieved February 05, 2013 from www. itp.net/news/510347-uae-leads-in-e-commerce-poll.

Harvard Business Review.

Hawk, S. (2004). A comparison of B2C e-commerce in developing countries. Electronic Commerce Research, 4 , 181-199. doi:10.1023/B:ELEC.0000027979.91972.36

International Telecommunications Union. (2009). Measuring the Information Society. The ICT Development Index, 2009 Edition. Retrieved May 10, 2013 from http://www.itu.int/ITU-D/ict/publications/idi/2009/ index.html.

Kalakota, R., \& Whinston, A. B. (1997). Electronic commerce: A manager's guide. MA: Addison-Wesley.

Karake-Shalhoub, Z., \& Al Qasimi, L. (2006). The diffusion of e-commerce in developing economies: a resource-based approach. London: Edward Elgar Publishing. doi:10.4337/9781847202994

Laudon, J., \& Laudon, K. (2008). Management Information Systems, Managing the Digital Firm (9th ed.). Trenton, NJ: Pearson Education.

Lee, C. S. (2001). An analytical framework for evaluating e-commerce business models and strategies. Internet Research,11(4),349.doi:10.1108/10662240110402803

MiniWatts Marketing Group. (2008). Internet usage in the Middle East. Internet World Stats. Retrieved June 10, 2013 from www.Internetworldstats.com/ stats5.htm\#top.

MiniWatts Marketing Group. (2008). Middle East - Saudi Arabia. Internet World Stats. Retrieved June 10, 2013 from www.Internetworldstats.com/middle.htm.

Molla, A., \& Heeks, R. (2007). Exploring E- Commerce Benefits for Businesses in a Developing Country. The Information Society, 23(2), 95-108. doi:10.1080/01972240701224028

Eid, M.I. (2011). Determinants of e-commerce customer satisfaction, trust and loyalty in Saudi Arabia. International Journal of Electronic Commerce, 12(1), 78-93.

New Zealand Trade and Enterprise. (2006). Saudi Arabia Country Brief. Retrieved April 23, 2013 from http://www.marketnewzealand.com/common/files/ saudiarabia-cb.pdf.

Paul, J. (2002). Narrowing the digital divide: Initiatives undertaken by the Association of South-East Asian Nations (ASEAN). Program: Electronic Library and Information Systems, 36(1), $13-22$. doi:10.1108/00330330210426085

Pons, A., Aljifri, H., \& Fourati, K. (2003). E-commerce and Arab Intra-trade. Information Technology\& People, 16(1), 34-48. doi:10.1108/09593840310463014

Postrel, V. (1998). A net of plenty. Forbes ASAP Supplement.

Sait, S. M., Al-Tawil, K. M., Sanaullah, S., \& Faheemud- din, M. (2007). Impact of Internet Usage in Saudi Arabia: A Social Perspective. International Journal of Information Technology and Web Engineering, 2(2), 81-115. doi:10.4018/jitwe.2007040104

Saudi Network Information Center. (2009). Saudi Do- mains Statistics. Retrieved April 10, 2013 from http:// www.nic.net.sa/page.php?page $=4 \&$ lang $=1$.

Sheth, J. N., \& Sharma, A. (2005). International e-marketing: Opportunities and issues. Inter- national Marketing Review, 22(6), 611-622. doi:10.1108/02651330510630249

Slywotzky, A. J. (2000). The future of commerce.

Smith, Q. (2008). Half of Saudi Internet users embrace e-commerce. ITP Digital, 18(17). Retrieved March 17, 2013 from http://www.itp.net/news/516867-half-of- saudi-Internet-users-embrace-e-commerce.

Turban, E., King, D., Lee, J. K., \& Viehland, D. (2006). Electronic Commerce 2006: A Managerial Perspective (4th ed.). Englewood Cliffs, NJ: Prentice-Hall. 